\title{
Schon fünf Minuten im Grünen hellen die Stimmung auf
}

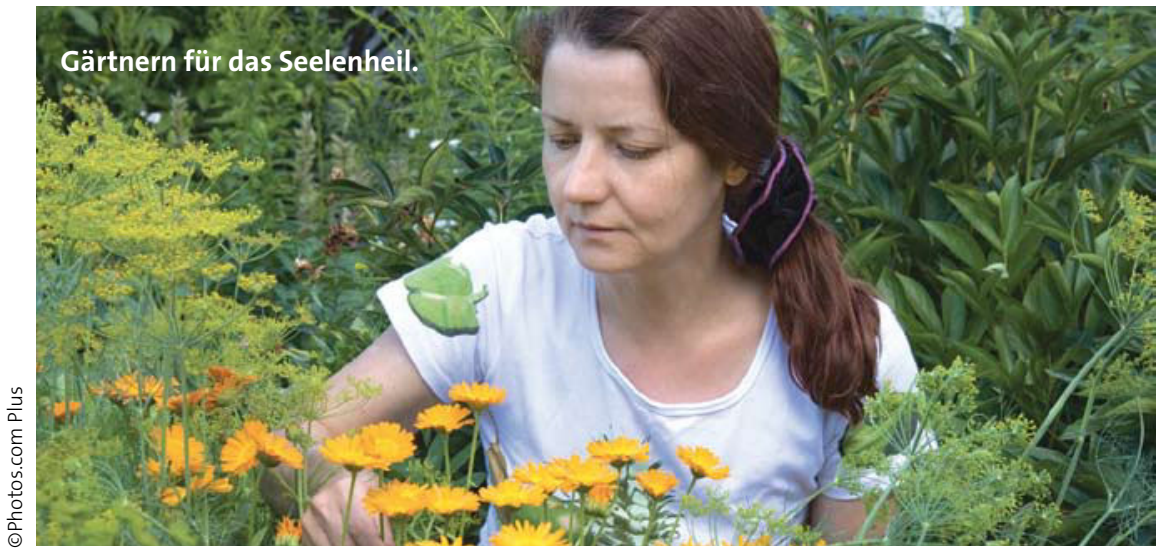

Der Aufenthalt im Grünen wirkt sich positiv auf die Psyche aus. Um eine therapeutisch wirksame Dosis zu erreichen, muss man nicht einmal viel Zeit investieren.

— In die Metaanalyse von zehn Studien gingen die Daten von 1252 Teilnehmern ein, darunter jugendliche Straftäter, psychisch Kranke, aber auch normale unauffällige Studenten. Die Probanden waren, bevor und nachdem sie verschiedenen Aktivitäten im Grünen nachgegangen waren, nach ihrer seelischen Verfassung gefragt worden.

Die Aktivitäten, denen die Probanden nachgingen, umfassten Wandern, Gartenarbeiten, Radfahren, Fischen, Bootfahren und Reiten. Diese Aktivitäten fanden in Stadtparks, in unberührter Natur oder in landwirtschaftlich genutzten Gebieten statt.

Wie sich zeigte, wirkt Grün auf Frauen und Männer in etwa gleich stark. Ein maximaler Effekt ist bereits nach fünf Minuten aktivem Aufenthalt im Grünen erreicht. Ein gemütlicher Spaziergang in der freien Natur ist genauso effektiv wie anstrengende Übungen im Grünen.

Besonders positiv scheint sich die Grüne Umgebung auf psychisch kranke Jugendliche auszuwirken. Die Art der Umgebung - Stadtpark, landwirtschaftlich genutztes Gebiet oder unberührte Natur - scheint nur eine untergeord- nete Rolle zu spielen. Allerdings verstärkt sich der positive Effekt, wenn das Grüngebiet an ein Gewässer grenzt.

\section{Kommentar}

Nach Meinung der Autoren ist dies die erste Studie, die eine dosisabhängige Beziehung zwischen einem Aufenthalt in der Natur und der psychischen Gesundheit zeigt. Stimmen die Daten, dann kann hier bereits in sehr geringer Zeit mit einem geringen Aufwand an körperlicher Aktivität ein maximaler Effekt erzielt werden.

K. MALBERG -

\footnotetext{
- J. Barton, J. Pretty

What is the best dose of nature and green exercise for improving mental health? A multi-study analysis. Environ. Sci. Technol. 44 (2010) 3947-3955
} 